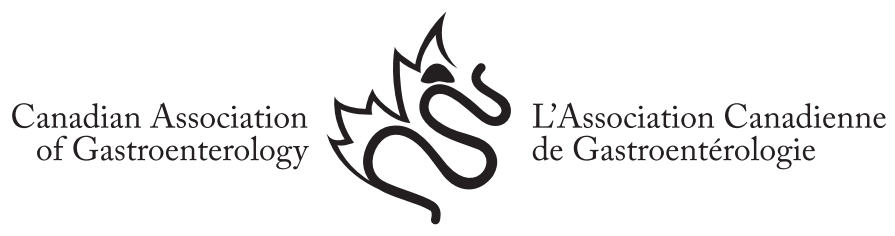

\title{
Call for nominations: The 2015 Canadian Association of Gastroenterology Research and Education Awards
}

$\mathrm{M}$ embers of the Canadian Association of Gastroenterology (CAG) are invited to nominate individuals for the 2015 CAG Research and Education Awards. All nominees must be members of the CAG. Descriptions of the awards, eligibility criteria and the process for nominating candidates are described below:

CAG Visiting Research Professorship - offered annually to a member who is a proven teacher and an outstanding researcher. The Visiting Research Professor visits several centers across Canada to present at gastroenterology or grand rounds, and/or research seminars. CAG Research Excellence Award - each year Research Affairs selects an outstanding Canadian researcher to present the annual research lecture at Canadian Digestive Diseases Week (CDDW).

CAG Young Investigator Award - recognizes outstanding contributions to gastroenterology through basic and/or clinical research by a young investigator, who is invited to give a lecture at CDDW. Candidates must:

- be younger than 45 years of age and/or within seven years of their first academic appointment;

- hold an appointment at a Canadian university, hospital or research institute

- be a Canadian citizen or a landed immigrant resident in Canada

CAG Visiting Clinical Professorship - offered annually to a member who is a proven educator and an outstanding clinician with interest in clinical research. The Visiting Clinical Professor will focus his or her visits to that of regional meetings/events versus academic sites.

CAG Education Excellence Award - offered annually for outstanding contributions to education on a national or international basis. The contribution may be in the areas of teaching, research in education or development of educational programs.

CAG Young Educator Award - recognizes outstanding contributions to gastroenterology through education by a young investigator who is invited to give a lecture at the Gastroenterology Residents-in-Training Course preceding CDDW. Candidates must:

- be younger than 45 years of age and/or within seven years of their first academic appointment;

- hold an appointment at a Canadian university, hospital or research institute; and

- be a Canadian citizen or a landed immigrant resident in Canada.

\begin{abstract}
Nominations process
More information on these awards, including a list of previous awardees, can be found on the CAG website at http://www.cag-acg.org/cagresearch-awards and http://www.cag-acg.org/awards.

Nominations for the above awards can be made by any member of the CAG by completing and submitting on-line the fillable PDF nomination form found on the CAG website at www.cag-acg.org (under 'Research', 'CAG Research Awards' or 'Education', 'Awards') or by sending the completed form by fax or e-mail to the CAG National Office:
\end{abstract}

CAG National Office

1540 Cornwall Road, Suite 224

Oakville, Ontario L6J 7W5

Fax: 905-829-0242

E-mail: cagoffice@cag-acg.org

For all nominations, a copy of the candidate's curriculum vitae and a letter of support should be forwarded (electronically) along with the nomination.

CAG Research and Education Affairs will review the nominations and make recommendations to the Board, who will make the final decision regarding recipients. Selection will be based on the research and/or education record of candidates.

The deadline for receipt of nominations is July 31, 2014.

\section{DON'T FORGET - CAG FELLOW NOMINATIONS}

To acknowledge continued service to the Association, as well as high standards of professionalism that it espouses, the CAG offers a professional designation: the Canadian Association of Gastroenterology Fellow (CAGF). This designation is awarded to physician or $\mathrm{PhD}$ members who have been Regular members for ten consecutive years and have served on a CAG committee or executive board for five years, which need not be consecutive. It is equally open to those in medical practice or research.

The deadline for 2015 nominations is October 1, 2014.

The CAG is proud to acknowledge its Benefactor Corporate Sponsors:

AbbVie Corporation

Olympus Canada Inc

Pentax Canada Inc

Janssen Inc

Takeda Canada Inc 


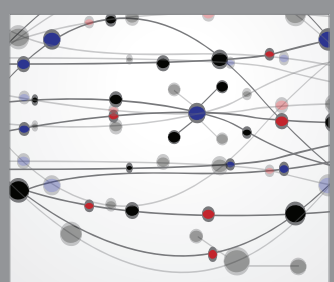

The Scientific World Journal
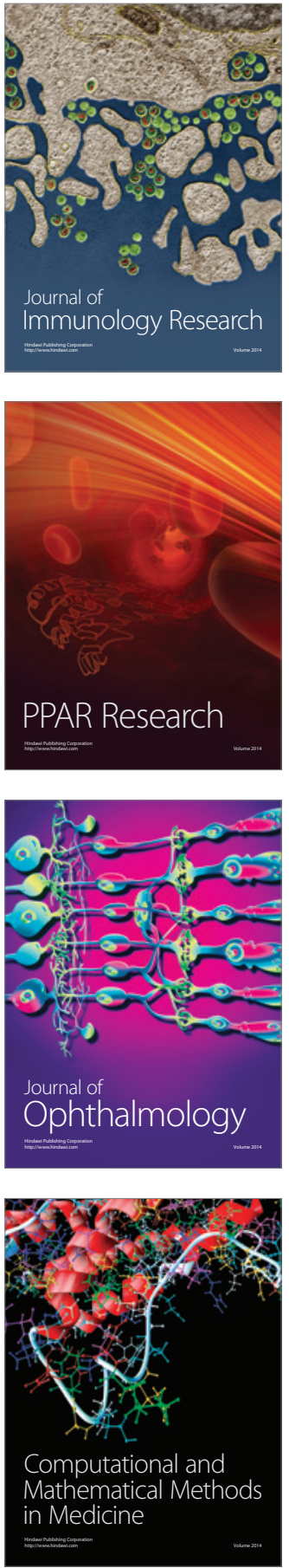

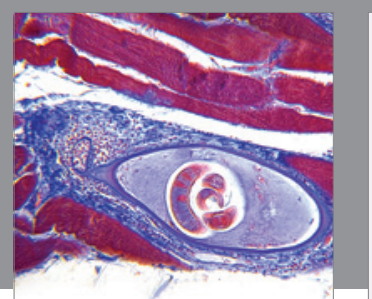

Gastroenterology Research and Practice

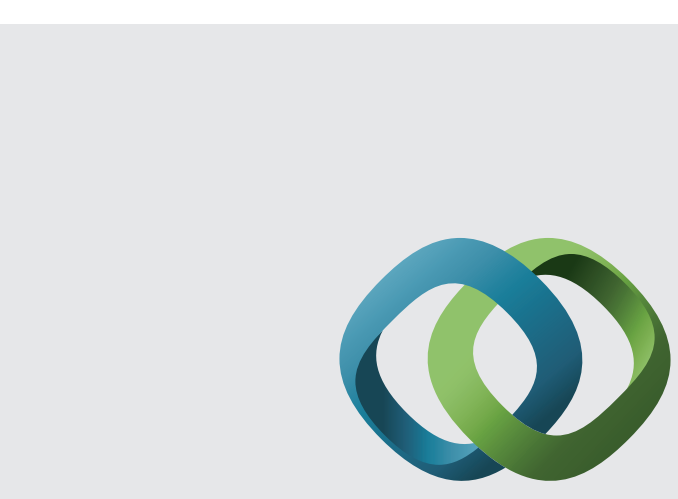

\section{Hindawi}

Submit your manuscripts at

http://www.hindawi.com
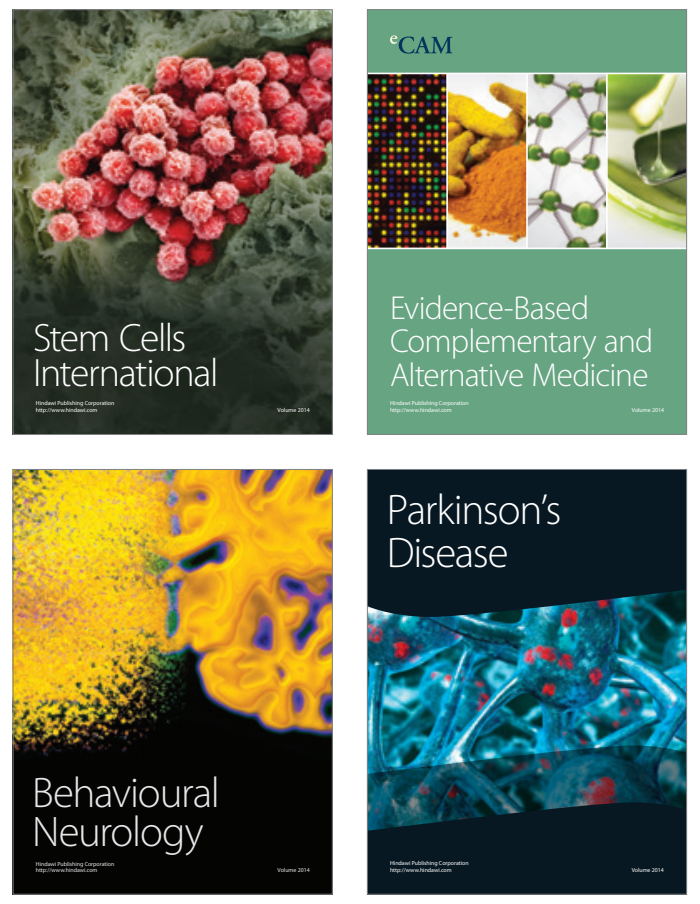
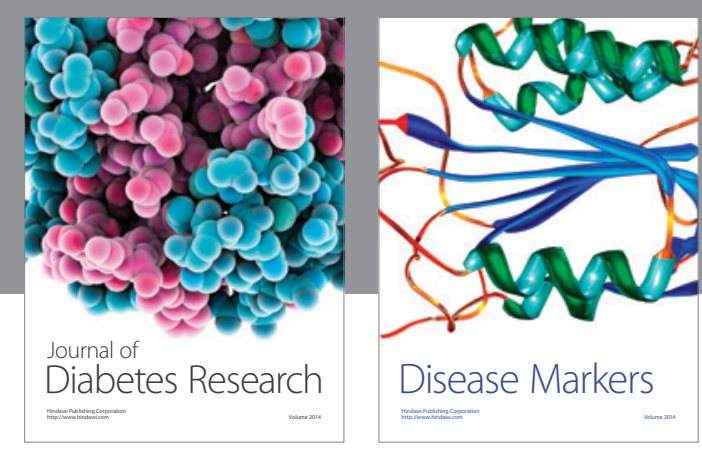

Disease Markers
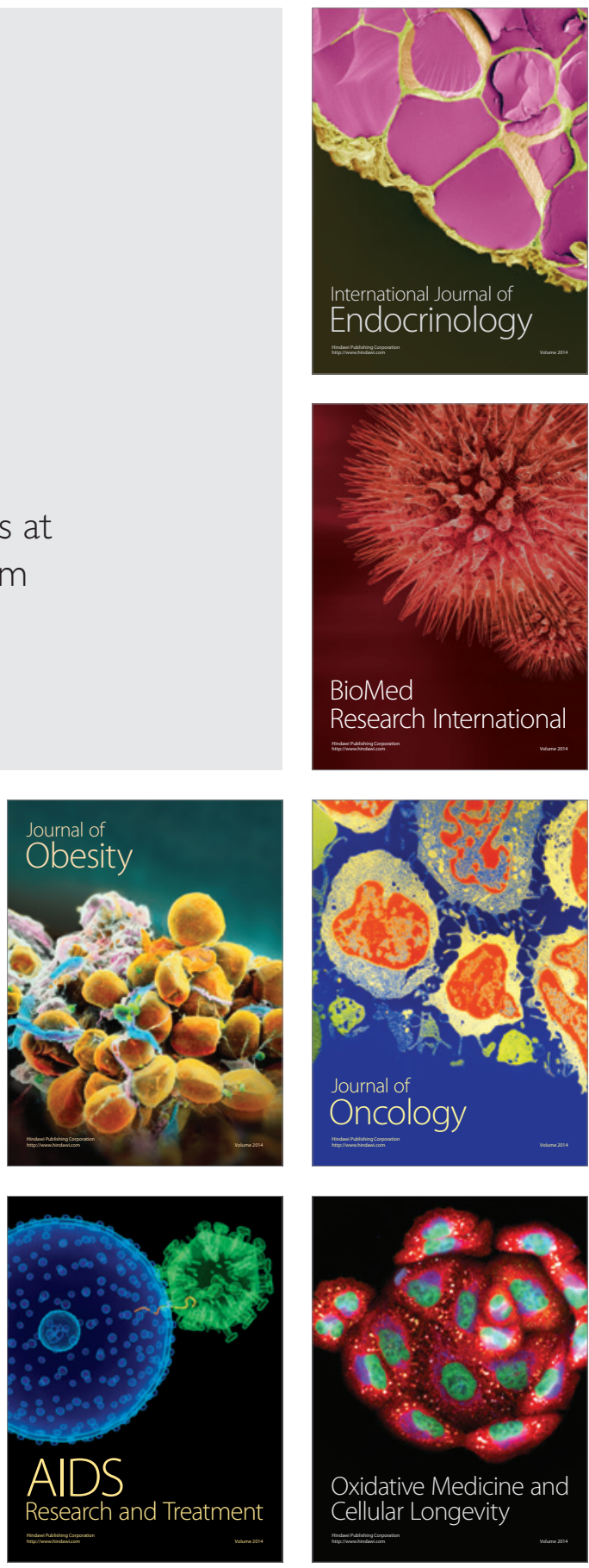